\title{
Crop to wild introgression in lettuce: following the fate of crop genome segments in backcross populations
}

\author{
Brigitte Uwimana', Marinus JM Smulders², Danny AP Hooftman ${ }^{3}$, Yorike Hartman ${ }^{4}$, Peter H van Tienderen ${ }^{4}$, \\ Johannes Jansen ${ }^{5}$, Leah K McHale ${ }^{6}$, Richard W Michelmore ${ }^{7}$, Richard GF Visser ${ }^{1}$ and Clemens CM van de Wiel ${ }^{2^{*}}$
}

\begin{abstract}
Background: After crop-wild hybridization, some of the crop genomic segments may become established in wild populations through selfing of the hybrids or through backcrosses to the wild parent. This constitutes a possible route through which crop (trans)genes could become established in natural populations. The likelihood of introgression of transgenes will not only be determined by fitness effects from the transgene itself but also by the crop genes linked to it. Although lettuce is generally regarded as self-pollinating, outbreeding does occur at a low frequency. Backcrossing to wild lettuce is a likely pathway to introgression along with selfing, due to the high frequency of wild individuals relative to the rarely occurring crop-wild hybrids. To test the effect of backcrossing on the vigour of inter-specific hybrids, Lactuca serriola, the closest wild relative of cultivated lettuce, was crossed with $L$. sativa and the $F_{1}$ hybrid was backcrossed to $L$. serriola to generate $B C_{1}$ and $B C_{2}$ populations. Experiments were conducted on progeny from selfed plants of the backcrossing families $\left(B C_{1} S_{1}\right.$ and $\left.B C_{2} S_{1}\right)$. Plant vigour of these two backcrossing populations was determined in the greenhouse under non-stress and abiotic stress conditions (salinity, drought, and nutrient deficiency).
\end{abstract}

Results: Despite the decreasing contribution of crop genomic blocks in the backcross populations, the $\mathrm{BC}_{1} \mathrm{~S}_{1}$ and $\mathrm{BC}_{2} \mathrm{~S}_{1}$ hybrids were characterized by a substantial genetic variation under both non-stress and stress conditions. Hybrids were identified that performed equally or better than the wild genotypes, indicating that two backcrossing events did not eliminate the effect of the crop genomic segments that contributed to the vigour of the $\mathrm{BC}_{1}$ and $\mathrm{BC}_{2}$ hybrids. QTLs for plant vigour under non-stress and the various stress conditions were detected in the two populations with positive as well as negative effects from the crop.

Conclusion: As it was shown that the crop contributed QTLS with either a positive or a negative effect on plant vigour, we hypothesize that genomic regions exist where transgenes could preferentially be located in order to mitigate their persistence in natural populations through genetic hitchhiking.

\section{Background}

One of the debated ecological risks associated with the commercial cultivation of genetically modified crop varieties is the possibility of introgression of transgenes from crops to their wild relatives through hybridization. Possible adverse consequences of introgression would be an increase in the weediness of the wild relatives in agricultural areas, genetic erosion in wild relatives, or the

\footnotetext{
* Correspondence: clemens.vandewiel@wur.nl

${ }^{2}$ Wageningen UR Plant Breeding, Postbus 16,6700AA Wageningen, the Netherlands

Full list of author information is available at the end of the article
}

invasion of new habitats by crop-wild transgenic lineages [1-4]. Where crops and their compatible wild relatives coexist, hybridization between the two is likely $[5,6]$. Therefore, the outcome of hybridization between crops and their wild relatives has been the subject of several research studies, using either transgenic or conventional crop varieties [7-10].

The net effect of crop-wild hybridization in terms of fitness may be negative, for instance if crop genes reduce the competitive ability under natural conditions, or positive, if hybrids inherit combinations of additive positive traits from the crop and the wild parents [11].

\section{() Biomed Central}


If hybrids are viable and fertile, hybridization can result in a swarm of hybrids in which crop and wild genomes interactively define the hybrid phenotypes. From the $F_{1}$ progeny onwards, crop alleles can be fixed through selfing or through backcrossing to the wild parent followed by selfing, or through combinations of these, depending on the breeding system of the species. Natural selection will purge maladapted genotypes, leaving those genotypes with similar or higher net fitness as the wild parent in the natural habitat of the wild taxon, or with broadened adaptation as a result of transgressive segregation [12,13].

Initially, any crop gene in a hybrid plant will be in a chromosome segment comprising the gene itself and other crop genes linked with it, and the fitness effect will depend on the overall effect of the whole chromosome segment [14]. In subsequent generations, these haplotypes will gradually be broken up through recombination, but loci at short genetic distances from each other may remain linked for many generations [15]. In the course of crop allele fixation, a gene that confers a selective advantage may be introgressed, but it will do so along with other loci tightly linked to it, which may also have an effect on fitness. A gene may also be selected against, if it is linked to a deleterious gene [16-18]. It is within such a context that the dynamics of the process of introgression from crops to wild relatives constitute a baseline for understanding the effects of transgene escape and fixation into wild taxa $[7,19]$.

We have initiated a study in which we follow the genetic process of introgression from cultivated lettuce (Lactuca sativa L.) to its wild relative prickly lettuce (Lactuca serriola L.). The two species readily hybridize, resulting in viable and fertile hybrids [20], hence representing a typical crop-weed complex. Despite the limited outcrossing rate in the two species [21,22], through population-genetic means we have identified crop-wild hybrid plants among natural populations of $L$. serriola which are expected to be a result of spontaneous gene flow between the two species [23].

In a previous study we have explored the genetic basis of hybrid vigour in an $F_{2}$ population resulting from a synthetic cross between cultivated $L$. serriola and $L$. sativa [Uwimana et al. submitted]. We mapped QTLs for plant vigour, which co-localized in a small number of chromosome regions, with genetic variation explained by both additive main effect and epistatic QTL effect. After hybridization, the crop genomic segments will be established in the wild background or eliminated by selection either through selfing of the hybrids or through backcrossing to the predominant wild plants, or a combination of the two processes. Selfing generations after a single hybridization event between the crop and the wild parents are characterized by crop genomic segments constituting an average of $50 \%$ of the hybrid genome. In contrast, every backcross to the wild parent decreases the crop genome content by half, while the crop genome segments become smaller through recombination (Additional file 1: Figure S1). In this way, crop segments that contribute to the vigour and fitness of the hybrids get introgressed with a decreasing number of hitchhiking loci with each backcross generation. Therefore, the fitness effects of a transgene in the context of its genomic location will differ in the selfing and backcrossing pathways.

Studies on crop-wild hybrids are usually conducted on selfing generations of the hybrids [7,8,24,25] and rarely on backcross populations [26], hence overlooking a significant pathway in the crop-to-wild introgression process. In this study we follow up the crop-weed complex of $L$. sativa and L. serriola in a marker-assisted introgression study, and we focus on $\mathrm{BC}_{1}$ and $\mathrm{BC}_{2}$ generations in which L. serriola was the recurrent parent, hence mimicking the introgression process from crops to wild relatives through repeated backcrosses with wild populations. Abiotic stresses constitute major selection factors that impact the frequency of specific crop segments in subsequent generations [27-29]. Moreover, considerable effort is presently put into developing transgenic varieties capable of withstanding abiotic stress factors [30,31]. Therefore, the two hybrid populations were tested under three abiotic stress conditions, namely drought, salinity and nutrient deficiency. We aimed at obtaining answers to the following questions: (1) Do the backcross generations exhibit transgressive segregation for vigour? (2) Are the vigour QTL regions that were identified in the selfing pathway $\left(\mathrm{F}_{2}\right.$ population) also detected in the backcross populations? (3) How does the contribution of crop alleles to the vigour of the hybrids change with the increasing proportion of wild genetic background?

\section{Results}

\section{Phenotypic variance among the hybrid families}

Backcrossing made the hybrid plants morphologically very similar to their wild parent, L. serriola. The $\mathrm{BC}_{1} \mathrm{~S}_{1}$ and $\mathrm{BC}_{2} \mathrm{~S}_{1}$ families showed a wide range of means for the vigour traits under stress and non-stress conditions (Table 1). Vigour depended on the backcross families and varied between the treatments in the two hybrid populations as revealed by the significance of GxE $\left(P_{\text {ge- }}\right.$ notype $\times$ treatment $<0.001$ for all traits). Some trait-treatment combinations, such as plant height under all the treatments and dry weight under control and drought conditions, showed transgressive segregation over the two parents (Table 1). For all traits and in both backcross generations the mean of the wild parent $L$. serriola was lower than the maximum mean of the hybrid 
Table 1 Parental means and mean, minimum and maximum values and heritability of the $B C_{1} S_{1}$ and $B C_{2} S_{1}$ families for vigour traits under non-stress, drought, salinity and nutrient deficiency conditions

\begin{tabular}{|c|c|c|c|c|c|c|c|}
\hline \multirow[b]{2}{*}{ Trait } & \multirow[b]{2}{*}{ Treatment } & \multirow[t]{2}{*}{ L. serriola } & \multirow[t]{2}{*}{ L. sativa } & \multicolumn{4}{|c|}{ Hybrid families } \\
\hline & & & & Mean & Min & Max & $\mathrm{H}^{2}$ \\
\hline & & & & \multicolumn{4}{|c|}{$\mathrm{BC}_{1} \mathrm{~S}_{1}$ families } \\
\hline \multirow[t]{5}{*}{ Plant height $(\mathrm{cm})$} & Control-D $^{1}$ & 31.42 & 23.52 & 30.87 & 27.43 & 36.19 & 0.86 \\
\hline & Drought & 16.58 & 13.19 & 16.05 & 13.53 & 18.53 & 0.74 \\
\hline & Control- SN & 33.36 & 17.95 & 28.75 & 22.39 & 42.64 & 0.95 \\
\hline & Salt & 16.72 & 14.70 & 17.18 & 13.40 & 24.93 & 0.95 \\
\hline & Nutrient deficiency & 10.57 & 8.75 & 10.07 & 7.88 & 13.35 & 0.86 \\
\hline \multirow[t]{5}{*}{ Fresh weight (g) } & Control-D & 39.20 & 68.11 & 46.56 & 25.25 & 62.26 & 0.87 \\
\hline & Drought & 6.48 & 8.01 & 6.46 & 5.40 & 8.14 & 0.48 \\
\hline & Control- SN & 25.52 & 39.15 & 27.24 & 21.76 & 32.27 & 0.79 \\
\hline & Salt & 8.40 & 20.13 & 10.85 & 7.90 & 14.35 & 0.69 \\
\hline & Nutrient deficiency & 2.60 & 4.82 & 3.16 & 2.46 & 3.92 & 0.44 \\
\hline \multirow[t]{5}{*}{ Dry weight (g) } & Control-D & 2.42 & 3.14 & 2.87 & 1.51 & 4.09 & 0.90 \\
\hline & Drought & 1.15 & 1.38 & 1.16 & 0.93 & 1.41 & 0.80 \\
\hline & Control-NS & 2.01 & 2.56 & 2.13 & 1.61 & 2.75 & 0.75 \\
\hline & Salt & 0.84 & 1.79 & 1.07 & 0.74 & 1.43 & 0.59 \\
\hline & Nutrient deficiency & 0.50 & 0.90 & 0.61 & 0.42 & 0.86 & 0.62 \\
\hline Relative moisture & Control-D & 93.80 & 95.41 & 93.89 & 93.07 & 94.83 & 0.75 \\
\hline \multirow[t]{5}{*}{ content (\%) } & Drought & 81.97 & 82.56 & 81.77 & 79.26 & 84.74 & 0.69 \\
\hline & Control-SN & 92.11 & 93.50 & 92.24 & 91.25 & 93.21 & 0.64 \\
\hline & Salt & 90.00 & 91.18 & 90.18 & 89.23 & 91.24 & 0.67 \\
\hline & Nutrient deficiency & $81.03^{\text {ns }}$ & 81.85 & 80.77 & 77.84 & 85.09 & 0.90 \\
\hline & & & & $\mathrm{BC}_{2} \mathrm{~S}_{1} \mathrm{f}$ & & & \\
\hline \multirow[t]{5}{*}{ Plant height $(\mathrm{cm})$} & Control-D ${ }^{1}$ & 27.93 & 23.07 & 29.17 & 24.09 & 37.01 & 0.85 \\
\hline & Drought & 14.02 & 12.32 & 14.32 & 12.39 & 17.75 & 0.77 \\
\hline & Control- SN & 21.02 & 16.63 & 21.51 & 17.51 & 28.04 & 0.80 \\
\hline & Salt & 16.54 & 13.62 & 16.54 & 13.01 & 22.2 & 0.84 \\
\hline & Nutrient deficiency & 11.62 & 10.07 & 11.33 & 9.69 & 14.05 & 0.43 \\
\hline \multirow[t]{5}{*}{ Fresh weight (g) } & Control-D & 27.21 & 67.25 & 38.59 & 23.38 & 54.89 & 0.73 \\
\hline & Drought & $5.24^{\text {ns }}$ & 5.46 & 4.55 & 3.31 & 6.32 & 0.37 \\
\hline & Control- SN & 13.70 & 31.32 & 17.64 & 13.19 & 26.39 & 0.72 \\
\hline & Salt & 9.31 & 17.87 & 10.35 & 7.27 & 13.36 & 0.63 \\
\hline & Nutrient deficiency & 4.87 & 7.14 & 5.34 & 4.26 & 7.65 & 0.59 \\
\hline \multirow[t]{5}{*}{ Dry weight (g) } & Control-D & 2.08 & 3.34 & 2.76 & 1.81 & 3.95 & 0.80 \\
\hline & Drought & $1.12^{\text {ns }}$ & 1.22 & 1.06 & 0.88 & 1.27 & 0.50 \\
\hline & Control-NS & 1.03 & 1.88 & 1.31 & 0.96 & 1.94 & 0.71 \\
\hline & Salt & 0.84 & 1.29 & 0.92 & 0.65 & 1.21 & 0.61 \\
\hline & Nutrient deficiency & 0.68 & 0.83 & 0.71 & 0.50 & 1.16 & 0.76 \\
\hline Relative moisture & Control-D & 92.28 & 95.06 & 92.86 & 92.06 & 94.03 & 0.78 \\
\hline \multirow[t]{4}{*}{ content (\%) } & Drought & $77.94^{\text {ns }}$ & 77.53 & 76.12 & 71.72 & 80.39 & 0.77 \\
\hline & Control-SN & 92.52 & 94.06 & 92.61 & 91.79 & 93.79 & 0.73 \\
\hline & Salt & 90.95 & 92.85 & 91.24 & 89.92 & 92.36 & 0.76 \\
\hline & Nutrient deficiency & 85.88 & 88.26 & 86.70 & 84.49 & 89.48 & 0.79 \\
\hline
\end{tabular}

1 Control-D: the control treatment of the drought experiment, Control-SN: the control treatment of the salt-nutrient experiment 
families. In spite of a second generation of backcrossing from $\mathrm{BC}_{1}$ to $\mathrm{BC}_{2}$, for each trait-treatment combination individual $\mathrm{BC}_{1} \mathrm{~S}_{1}$ and $\mathrm{BC}_{2} \mathrm{~S}_{1}$ plants and families stood out that performed better than the two wild genotypes (L. serriola/Eys and L. serriola acc. UC96US23, Table 1 and Additional file 1: Figures S3 and Figure S4), indicating that the $\mathrm{BC}_{2}$ plants still contained crop genomic segments which contributed positively to their vigour.

Genetic variation as measured through the broad sense heritability of family means of the traits ranged from 0.44 to 0.95 in the $\mathrm{BC}_{1}$ experiments, showing that a substantial part of the phenotypic variation was due to genetic factors (Table 1). In the drought experiment, heritability was lower in the drought treatment than in the control for all traits. In the salt-nutrient experiment, the heritability was lower in the salt and nutrient deficiency treatment than in the control for plant height, fresh weight and dry weight, but the heritability was higher for relative moisture content, with a greater difference in the nutrient deficiency treatment $(0.90 \mathrm{com}$ pared to 0.64 in the control).

In the $\mathrm{BC}_{2}$ population, heritability of the traits among $\mathrm{BC}_{2} \mathrm{~S}_{1}$ families ranged from 0.43 to 0.85 , which is comparable to the range found in the $\mathrm{BC}_{1}$ population (Table 1). Also in line with the $\mathrm{BC}_{1}$ population, the heritability was lower in the drought treatment than in the control for all the traits in the $\mathrm{BC}_{2}$ population. In the salt-nutrient experiment, heritability was lower in the salt treatment than in the control for fresh weight and dry weight, while it was slightly higher than the control for plant height and relative moisture content. In the same experiment, heritability was considerably lower under nutrient deficiency conditions as compared to the control for plant height, with 0.85 under control and 0.43 under nutrient deficiency conditions.

\section{Allelic composition of the hybrids and linkage maps}

$\mathrm{BC}_{1}$ individuals contained on average $26 \%$ of the crop genome with individual plants ranging from $11 \%$ to $39 \%$. The population was characterized by long crop genomic segments in a heterozygous state which sometimes spanned all the markers of a whole linkage group (Additional file 1: Figure S2A). One additional backcross to the wild parent resulted in a reduction of the crop genome content to $14 \%$, varying among $\mathrm{BC}_{2}$ individuals both in segment size and proportion, ranging from 3\% to 29\% (Additional file 1: Figure S2B).

The linkage maps, shown in Figures 1, 2, 3, 4 and 5, consisted of nine linkage groups (LG) that represented the nine chromosomes of lettuce [32]. The same marker order was obtained in the $\mathrm{BC}_{1}$ and $\mathrm{BC}_{2}$ populations. The $\mathrm{BC}_{1}$ map was made of 347 markers spanning a total length of $1301 \mathrm{cM}$, while the $\mathrm{BC}_{2}$ map had 348 markers with a total length of $1403 \mathrm{cM}$. Individual linkage groups contained 34 to 50 SNP markers, except LG9, which had 18 markers. As mentioned in the QTL analysis subsection of Materials and Methods, virtual markers were added on the $\mathrm{BC}_{2}$ map to fill gaps stemming from the additional round of recombination for better QTL mapping results. These markers are underlined on the $\mathrm{BC}_{2}$ linkage map (Figures 1, 2, 3, 4 and 5).

\section{Quantitative Trait Loci}

Twenty QTLs associated with plant vigour were mapped in the $\mathrm{BC}_{1}$ population, 5 for plant height, 4 for fresh weight, 4 for dry weight and 7 for relative moisture content (Table 2 and Figures 1, 2, 3, 4 and 5). The QTLs were located on all linkage groups except LG2. Only three of these QTLs had the same order of magnitude additive effect in all treatments. The remaining QTLs were significantly affected by QTLxE.

QTLs for plant height had an additive effect positive for the wild allele in the drought and salt treatments, and in the two control treatments. Under nutrient deficiency, two of the plant height QTLs had an additive effect positive for the wild allele, while three QTLs for the same trait were positive for the crop allele, including two QTLs (L-3-3 and L-7-1) which had a positive effect for the wild allele in other treatments, hence showing opposite allelic effects from one treatment to another.

Fresh weight QTLs were inherited from the crop as three of the QTLs for this trait showed a positive additive effect for the crop allele. Dry weight QTLs were inherited from both the crop and wild parent as three of the QTLs for the trait had a positive additive effect for the crop allele, while one QTL for that trait showed a positive additive effect for the wild allele. Relative moisture content QTLs were inherited from both the crop and the wild parents. Four of the QTLs mapped for this trait had a positive additive effect for the crop allele, while the additive effect was positive for the wild allele for the remaining three QTLs.

Fewer QTLs were mapped in the $\mathrm{BC}_{2}$ than in the $\mathrm{BC}_{1}$ population (Table 2 and Figures 1, 2, 3, 4 and 5). Thirteen QTLs were mapped in $\mathrm{BC}_{2}$ for vigour-related traits. Four of the QTLs were significant in all the treatments with the same additive effect, hence having non-significant QTLxE effect, while the remaining nine were significantly affected by QTLxE.

Two of the QTLs for plant height had a positive additive effect for the wild allele and they were significant under the control treatment of the salt-nutrient experiment and under salt treatment. The other two had a positive additive effect for the crop allele. The three fresh weight QTLs had a positive additive effect for the crop allele. For the dry weight QTLs, one had a positive additive effect from the crop allele and the other one was positive for the wild allele. Relative moisture content QTLs were inherited from both the wild and the crop parent. 


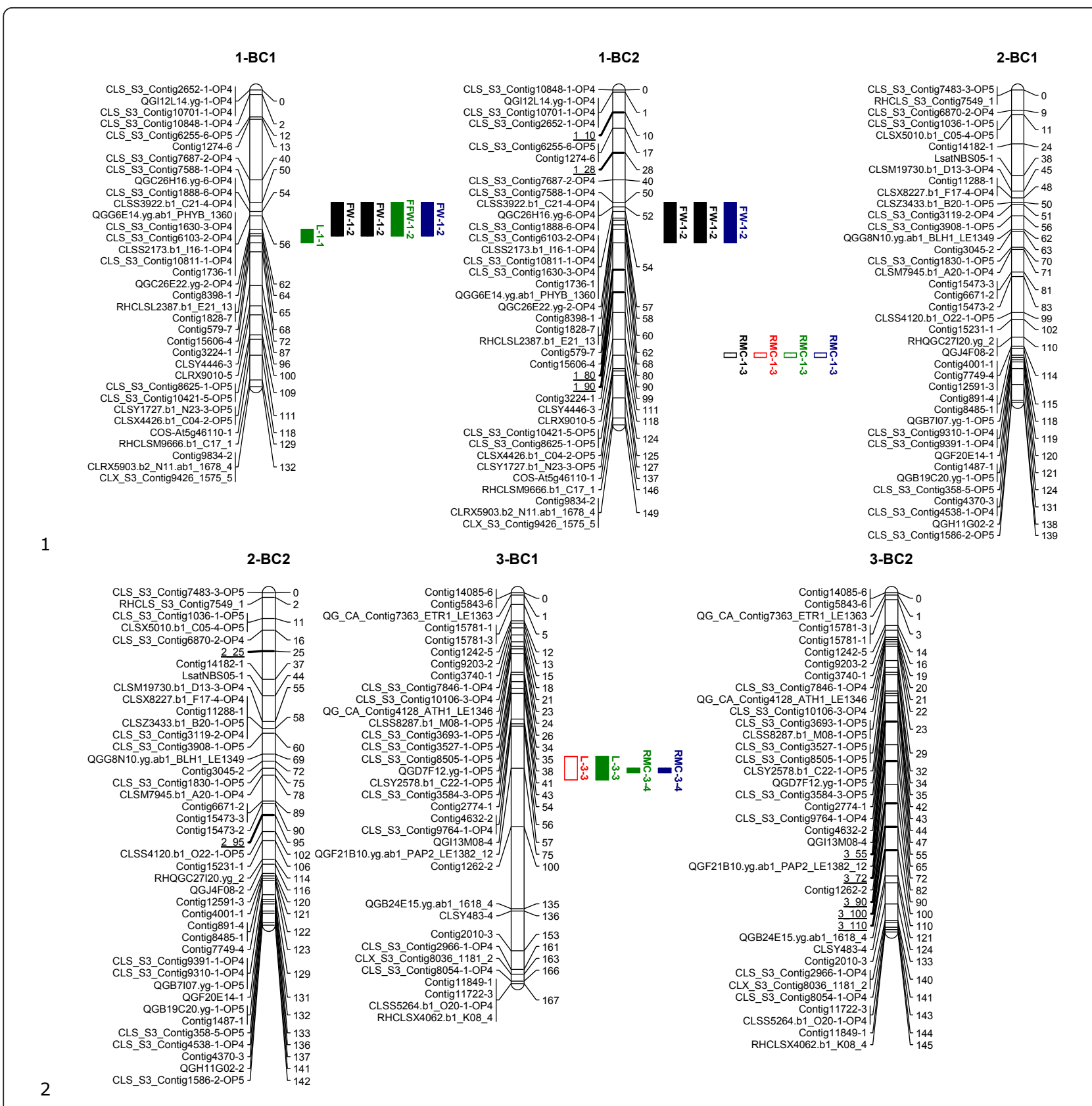

Figure 1 Linkage maps of the $\mathrm{BC}_{1}$ and $\mathrm{BC}_{2}$ populations based on 100 and 458 individuals respectively: Linkage groups 1-3. Markers are shown on the left of the bar and their positions on the right in $\mathrm{CM}$. The added virtual markers on the $\mathrm{BC}_{2}$ map with missing scores are underlined. Vigour QTLs as mapped in $\mathrm{BC}_{1} \mathrm{~S}_{1}$ and $\mathrm{BC}_{2} \mathrm{~S}_{1}$ families under non-stress (black), drought (red), salt (blue) and nutrient deficiency (green) conditions are shown next to the marker positions. Open QTL block indicates a positive additive effect for the wild allele, and closed QTL block indicates a positive additive effect for the crop allele. Trait abbreviations: L: plant length, FW: fresh weight, DW: dry weight, RMC: relative moisture content.

\section{Co-localization of QTL regions}

QTL regions on LG4 and LG7 were the most important in the two populations as they comprised most of the QTLs. Four QTLs were mapped on the same region on $\mathrm{LG} 7$ in the $\mathrm{BC}_{1}$ and $\mathrm{BC}_{2}$ populations, one for each of the measured vigour traits (Figure 4). The
QTLs for fresh weight and dry weight had the same allelic effect, which was positive for the crop allele under all the treatments. However, the plant height and relative moisture content QTLs showed allelic specificity for treatments in the two populations, with a QTL showing a positive effect from one parent in one 


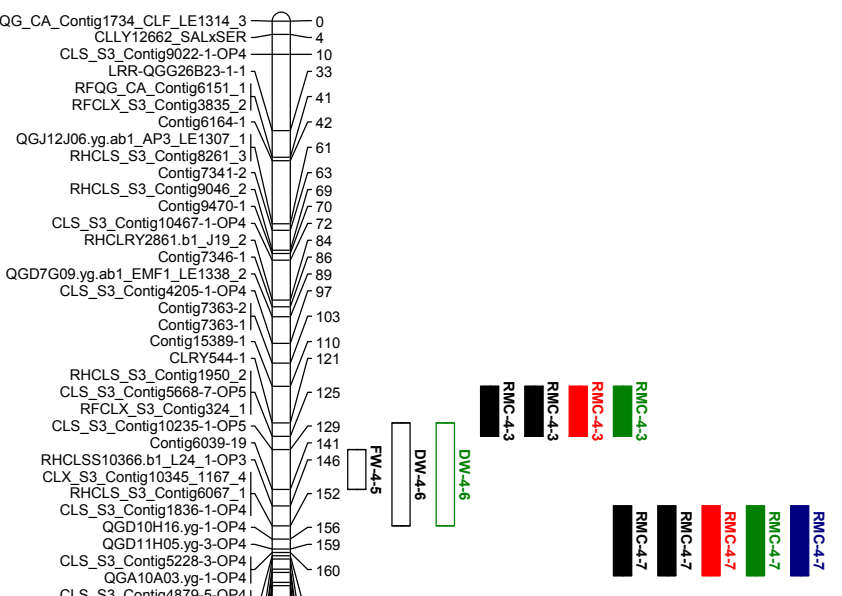

3

CLSY3580.b1_H07-2-OP4

CLSX5012.61_G05-1-OP4

CLSS10585.b Contiga579-2

CLS_S3_Contig9866-2-OP4

CLS_S3_Contig6264-3-OP4

CLS_S3 Contig4328-2-OP5

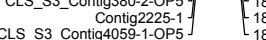

4-BC2

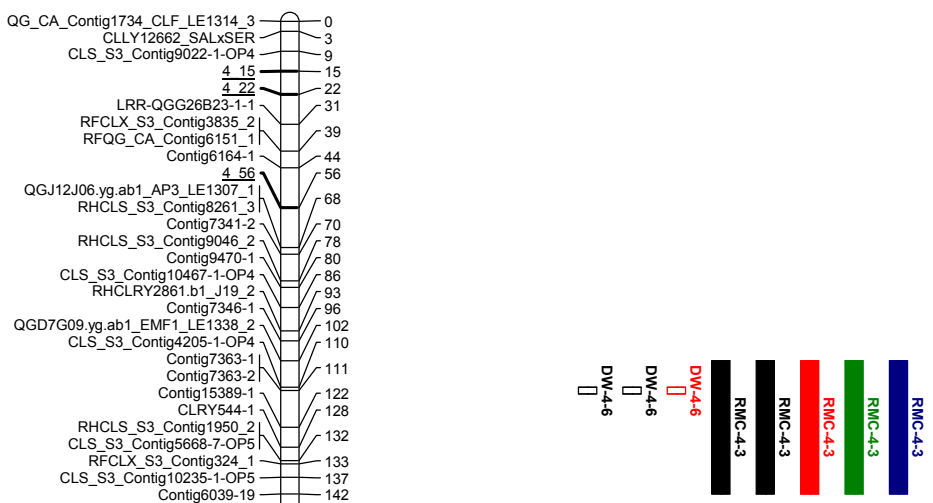

RHCLSS10366.b1_L24_1-OP3 ${ }^{142}$

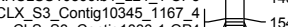

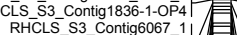

QGA10A03.yg-1-OP4

CLS_S3 Contig5228-3-OP4

$\left.\begin{array}{c}\text { QGD 10H16.yg-1-OP4 } \\ \text { CLSY3580.b1 H07-2-OP4 }\end{array}\right)=\left(\begin{array}{l}156 \\ 150\end{array}\right.$

CLSS10585.b1_A08-2-OPA

CLSX5012.61-G05-1-OP4

CLS_S3_Contig4879-5-OP4 OM $^{157}$

Contig9579-2 CLS_S3_Contig2084-1-OP4

161

CLS_S3_Contig4328-2-OP5
CLSM19998.61 K07-2-OP5

CLS_S3_Contig4059-1-1-20P5

Contig2225-1

4

CLS_S3_Contig $380-\frac{4}{2-O P 5}$.

$=-\frac{5}{2}-\frac{5}{2}=-\frac{5}{2}-\frac{5}{2}-\frac{5}{2}$

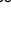

58

62

-164
174
184

-184
-185
194
203

Figure 2 Linkage maps of the $B_{1}$ and $B C_{2}$ populations based on 100 and 458 individuals, respectively: Linkage group 4 . Markers are shown on the left of the bar and their positions on the right in $\mathrm{CM}$. The added virtual markers on the BC2 map with missing scores are underlined. Vigour QTLs as mapped in $\mathrm{BC}_{1} \mathrm{~S}_{1}$ and $\mathrm{BC}_{2} \mathrm{~S}_{1}$ families under non-stress (black), drought (red), salt (blue) and nutrient deficiency (green) conditions are shown next to the marker positions. Open QTL block indicates a positive additive effect for the wild allele, and closed QTL block indicates a positive additive effect for the crop allele. Trait abbreviations: L: plant length, FW: fresh weight, DW: dry weight, RMC: relative moisture content 


\section{5-BC1}
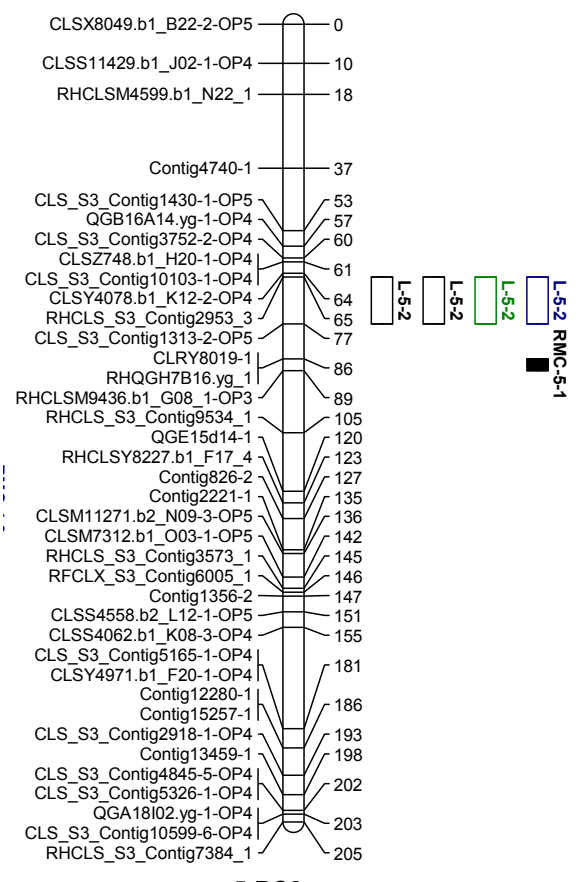

5-BC2

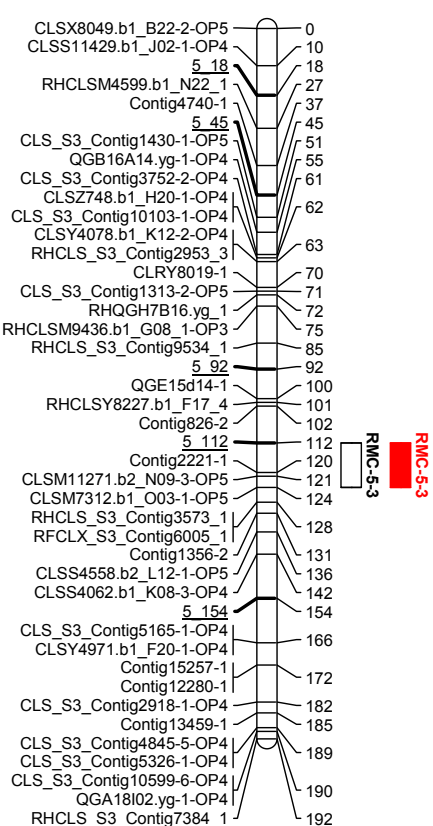

6-BC1

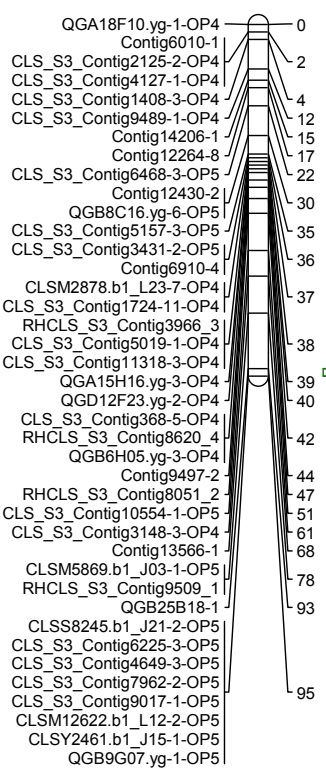

6-BC2

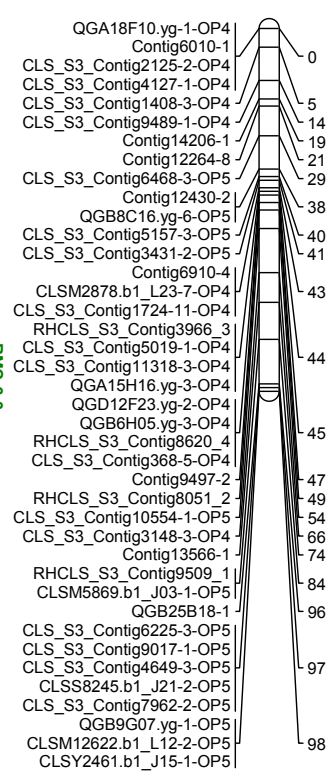

6

Figure 3 Linkage maps of the $\mathrm{BC}_{1}$ and $\mathrm{BC}_{2}$ populations based on 100 and 458 individuals, respectively: Linkage groups 5-6. Markers are shown on the left of the bar and their positions on the right in $\mathrm{CM}$. The added virtual markers on the $\mathrm{BC}_{2}$ map with missing scores are underlined. Vigour QTLs as mapped in $\mathrm{BC}_{1} \mathrm{~S}_{1}$ and $\mathrm{BC}_{2} \mathrm{~S}_{1}$ families under non-stress (black), drought (red), salt (blue) and nutrient deficiency (green) conditions are shown next to the marker positions. Open QTL block indicates a positive additive effect for the wild allele, and closed QTL block indicates a positive additive effect for the crop allele. Trait abbreviations: L: plant length, FW: fresh weight, DW: dry weight, RMC: relative moisture content. 


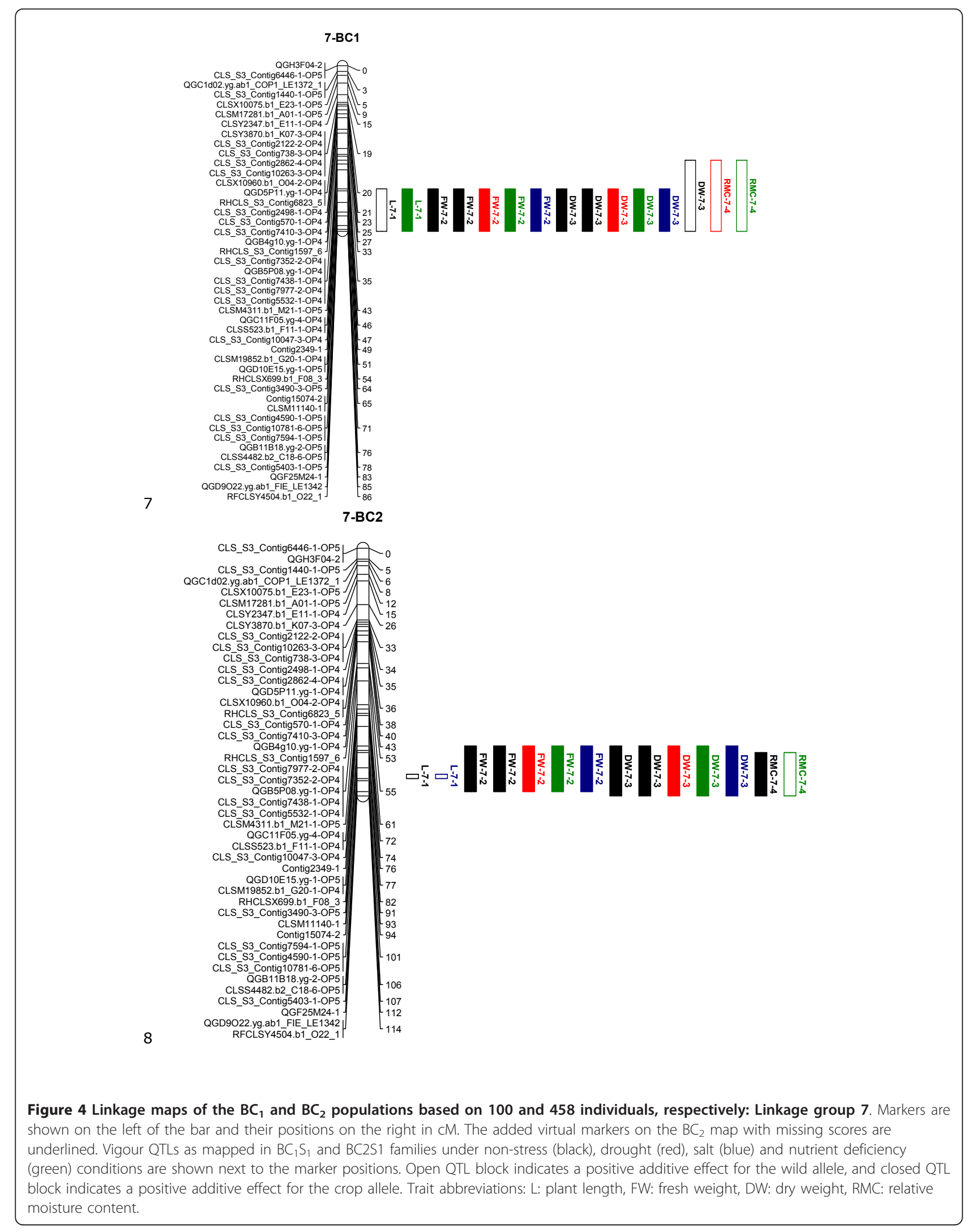




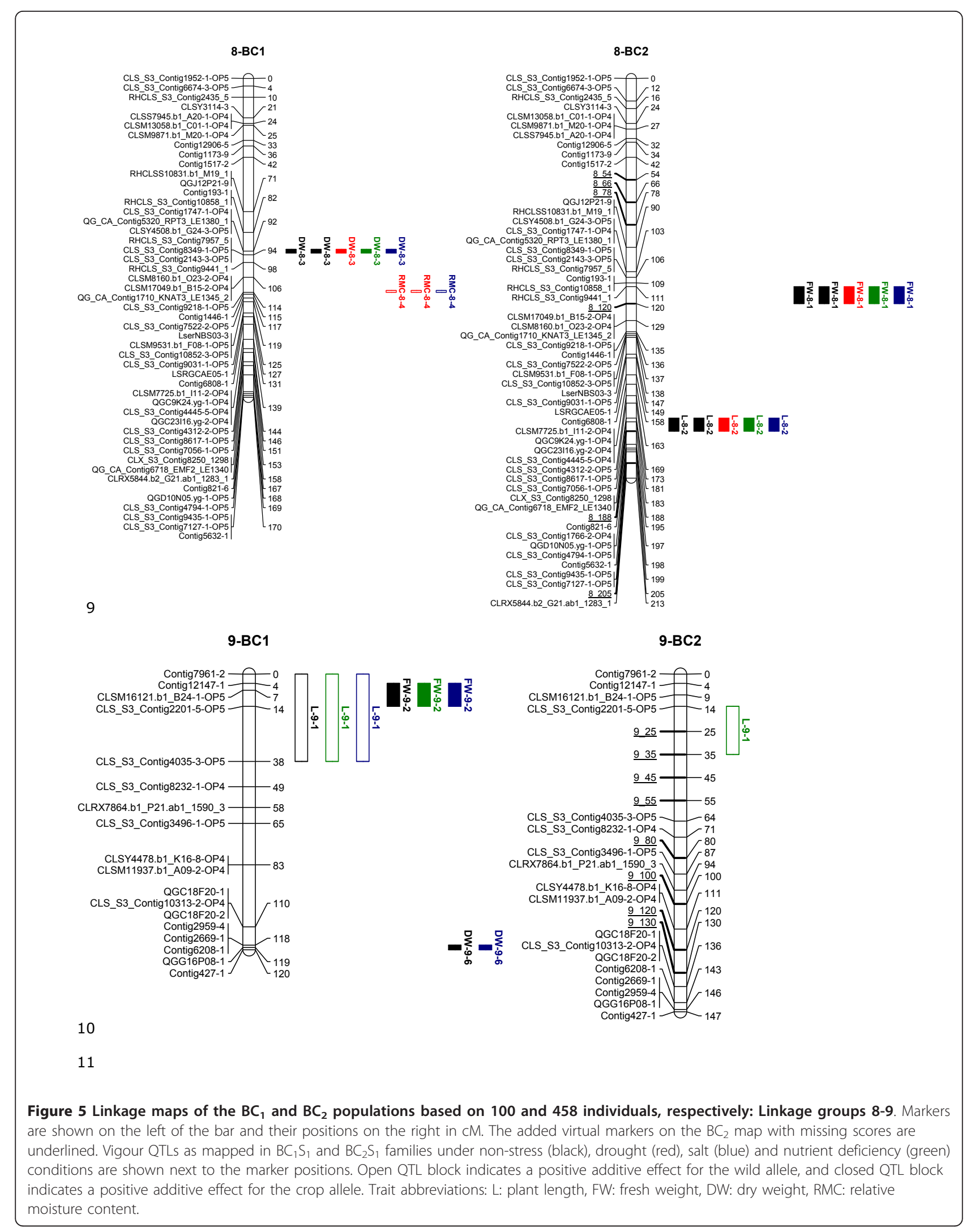


Table 2 Quantitative trait loci mapped in $100 \mathrm{BC}_{1} \mathrm{~S}_{1}$ and $100 \mathrm{BC}_{2} \mathrm{~S}_{1}$ families for vigour traits under non-stress, drought, salt and nutrient deficiency conditions

\begin{tabular}{|c|c|c|c|c|c|c|c|c|c|c|}
\hline \multirow[b]{2}{*}{ Trait } & \multirow[b]{2}{*}{ Pop. } & \multirow[b]{2}{*}{ QTLname } & \multirow[b]{2}{*}{ Most significant marker } & \multirow[b]{2}{*}{ LG } & \multirow[b]{2}{*}{ QTLxE } & \multicolumn{5}{|c|}{$\begin{array}{l}\text { Additive effect for the crop allele (\% } \\
\text { explained variance) }\end{array}$} \\
\hline & & & & & & $C-D^{1}$ & D & C-SN & $\mathrm{N}$ & $\mathrm{S}$ \\
\hline \multirow[t]{9}{*}{ Plant height $(\mathrm{cm})$} & $\mathrm{BC}_{1}$ & $L-7-1$ & QGF25M24-1 & 7 & yes & & & $-2.06(6)$ & $0.39(3)$ & \\
\hline & & $L-9-1$ & CLS_S3_Contig2201-5-OP5 & 9 & yes & & & $\begin{array}{l}-4.61 \\
(32)\end{array}$ & $\begin{array}{l}-0.79 \\
(13)\end{array}$ & $\begin{array}{l}-2.32 \\
(30)\end{array}$ \\
\hline & & $L-1-1$ & QGC26E22.yg-2-OP4 & 1 & yes & & & & $0.74(12)$ & \\
\hline & & $L-3-3$ & QGF21B10.yg.ab1_PAP2_LE1382_12 & 3 & yes & & $-0.48(6)$ & & $0.39(3)$ & \\
\hline & & $L-5-2$ & CLS_S3_Contig1313-2-OP5 & 5 & yes & $\begin{array}{l}-1.19 \\
(11)\end{array}$ & & $-1.72(4)$ & $-0.49(5)$ & $\begin{array}{l}-1.53 \\
(13)\end{array}$ \\
\hline & $\mathrm{BC}_{2}$ & $L-7-1$ & QGB11B18.yg-2-OP5 & 7 & yes & & & $-1.30(4)$ & & $-0.73(3)$ \\
\hline & & $L-9-1$ & CLS_S3_Contig2201-5-OP5 & 9 & yes & & & & & $-0.53(3)$ \\
\hline & & $L-4-4$ & Contig1094-1 & 4 & no & $0.42(1)$ & $0.42(6)$ & $0.42(1)$ & $0.42(9)$ & $0.42(2)$ \\
\hline & & $L-8-2$ & CLX_S3_Contig8250_1298 & 8 & yes & $1.46(8)$ & $0.72(14)$ & 1.87(19) & $0.38(6)$ & $1.57(24$ \\
\hline \multirow[t]{7}{*}{ Fresh weight (g) } & $\mathrm{BC}_{1}$ & $F W-7-2$ & CLSS4482.b2_C18-6-OP5 & 7 & yes & $4.02(10)$ & $0.20(4)$ & $0.96(4)$ & $0.34(27)$ & $1.28(22)$ \\
\hline & & $F W-9-2$ & CLS_S3_Contig2201-5-OP5 & 9 & yes & $2.38(3)$ & & & $0.27(17)$ & $0.48(3)$ \\
\hline & & $F W-1-2$ & QGG6E14.yg.ab1_PHYB_1360 & 1 & yes & $4.32(11)$ & & $1.50(11)$ & $0.14(4)$ & $0.92(11)$ \\
\hline & & $F W-4-5$ & Contig6039-19 & 4 & yes & $3.04(6)$ & & & & \\
\hline & $\mathrm{BC}_{2}$ & $F W-7-2$ & CLS_S3_Contig7594-1-OP5 & 7 & no & $0.28(1)$ & $0.28(9)$ & $0.28(1)$ & $0.28(5)$ & $0.28(1)$ \\
\hline & & $F W-1-2$ & CLSS3922.b1_C21-4-OP4 & 1 & yes & $2.73(7)$ & & $2.29(19)$ & & $0.97(19)$ \\
\hline & & $F W-8-1$ & RHCLS_S3_Contig9441_1 & 8 & no & $0.32(1)$ & $0.32(13)$ & $0.32(1)$ & $0.32(7)$ & $0.32(2)$ \\
\hline \multirow[t]{6}{*}{ Dry weight (g) } & $\mathrm{BC}_{1}$ & $D W-7-3$ & CLSS4482.b2_C18-6-OP5 & 7 & no & $0.08(1)$ & $0.08(15)$ & $0.08(3)$ & $0.08(19)$ & $0.08(8)$ \\
\hline & & $D W-4-6$ & CLRY544-1 & 4 & yes & $\begin{array}{l}-0.39 \\
(16)\end{array}$ & & $-0.04(4)$ & $-0.04(4)$ & \\
\hline & & DW-8-3 & QG_CA_Contig5320_RPT3_LE1380_1 & 8 & no & $0.05(1)$ & $0.05(6)$ & $0.05(1)$ & $0.05(7)$ & $0.05(3)$ \\
\hline & & DW-9-6 & QGG16P08-1 & 9 & yes & & & $-0.09(4)$ & & $0.04(6)$ \\
\hline & $\mathrm{BC}_{2}$ & $D W-7-3$ & QGF25M24-1 & 7 & no & $0.07(1)$ & $0.07(25)$ & $0.07(4)$ & $0.07(12)$ & $0.07(9)$ \\
\hline & & $D W-4-6$ & Contig7363-2 & 4 & yes & $-0.21(6)$ & $\begin{array}{l}-0.06 \\
(15)\end{array}$ & $-0.11(8)$ & & \\
\hline \multirow{11}{*}{$\begin{array}{l}\text { Relative moisture content } \\
(\%)\end{array}$} & $\mathrm{BC}_{1}$ & $R M C-4-3$ & CLRY544-1 & 4 & yes & $0.24(9)$ & $0.60(6)$ & $0.15(4)$ & $1.18(17)$ & \\
\hline & & $R M C-5-1$ & RHCLSM9436.b1_G08_1-OP3 & 5 & yes & $0.25(10)$ & & & & \\
\hline & & $R M C-7-4$ & CLSS4482.b2_C18-6-OP5 & 7 & yes & & $-0.73(9)$ & $-0.17(6)$ & $-0.85(9)$ & \\
\hline & & $R M C-3-4$ & QGF21B10.yg.ab1_PAP2_LE1382_12 & 3 & yes & & & & $0.79(8)$ & $0.18(5)$ \\
\hline & & RMC-4-7 & CLX_S3_Contig10345_1167_4 & 4 & no & $0.22(7)$ & $0.22(1)$ & $0.22(10)$ & $0.22(1)$ & $0.22(4)$ \\
\hline & & $R M C-6-3$ & QGB25B18-1 & 6 & yes & & & & $\begin{array}{l}-1.19 \\
(17)\end{array}$ & \\
\hline & & $R M C-8-4$ & CLS_S3_Contig9218-1-OP5 & 8 & yes & & $\begin{array}{l}-0.81 \\
(11)\end{array}$ & & $0.46(3)$ & $-0.17(4)$ \\
\hline & $\mathrm{BC}_{2}$ & $R M C-4-3$ & Contig15389-1 & 4 & yes & $0.32(19)$ & $1.16(14)$ & $0.27(16)$ & $0.89(23)$ & $0.27(9)$ \\
\hline & & RMC-7-4 & QGF25M24-1 & 7 & yes & $0.19(7)$ & & & $-0.56(9)$ & \\
\hline & & $R M C-1-3$ & CLRX9010-5 & 1 & yes & & $\begin{array}{l}-1.33 \\
(19)\end{array}$ & $-0.16(5)$ & $\begin{array}{l}-0.60 \\
(11)\end{array}$ & $-0.24(8)$ \\
\hline & & $R M C-5-3$ & Contig2221-1 & 5 & yes & & $0.72(6)$ & $-0.21(9)$ & & \\
\hline
\end{tabular}

1 C-D: control treatment of the drought experiment; D: drought, C-SN: control treatment of the salt-nutrient experiment, N: nutrient deficiency, S: salt

treatment and a positive effect for a different treatment from the other parent. On LG4, four QTLs were mapped around the same region in $\mathrm{BC}_{1}$ and the same region contained three QTLs in $\mathrm{BC}_{2}$, including two
QTLs that were common in the two populations. In total 8 QTLs were common in the $\mathrm{BC}_{1}$ and $\mathrm{BC}_{2}$ populations on LG1, LG4, LG7, and LG9. Additionally, a QTL region was found in both populations on LG8 
but it contained QTLs for different traits in the two populations.

\section{QTL epistatic effects}

QTL epistatic effects on the vigour traits were significant in the two hybrid populations and under stress and non-stress conditions. In the $\mathrm{BC}_{1}$ population epistasis was estimated for 10 QTL pairs and it explained 4 to 9\% of the phenotypic variance per individual QTL pair and up to $23 \%$ per trait. Nine QTL regions were used in the $\mathrm{BC}_{2}$ population, supplemented with 6 QTL regions that, on their own, were only significant in the $\mathrm{BC}_{1}$, in order to increase the number of loci in the epistasis analysis. Epistasis for these regions explained 3 to $11 \%$ of the phenotypic variance per QTL pair and up to $27 \%$ per trait (Table 3). While interacting QTLs for plant height had a higher mean for the crop-crop or wild-wild genotype combinations in the $\mathrm{BC}_{1}$ population, the highest mean for the same trait was associated with cropwild genotype combinations in the $\mathrm{BC}_{2}$ population, showing the effect of the combination of QTLs inherited from the two parents for that trait. The genotype combination of a wild allele at the two epistatic loci (b/b) was associated with the highest mean for 3 out of 17 QTL pairs in $\mathrm{BC}_{1}$ and 3 out of 23 QTL pairs in $\mathrm{BC}_{2}$, indicating that the advantageous epistatic effect was mostly associated with the genotype combinations involving a crop allele at one of the two loci.

\section{Discussion}

\section{Performance of crop-wild hybrid lines}

Studies on introgression of crop genes into wild relative genomes have shown that although the average fitness of the hybrids might be lower than the fitness of the wild relative, individual hybrid genotypes could have similar or better fitness than their wild parent, showing a potential for introgression of advantageous crop genes $[33,34]$. In our study, the $\mathrm{BC}_{1} \mathrm{~S}_{1}$ and $\mathrm{BC}_{2} \mathrm{~S}_{1}$ families revealed lines showing transgressive segregation for vigour in the control and stress treatments, indicating that two generations of backcrossing to the wild parent did not eliminate the effect of the crop segments. The occurrence of $\mathrm{BC}_{2} \mathrm{~S}_{1}$ families that outperform the wild parent shows that if vigour traits positively correlate with fitness under natural conditions, crop genomic segments that confer improved vigour could be introgressed into the wild taxon, rendering it more vigorous under non-stress as well as under abiotic stress conditions.

\section{QTL effects}

Backcrossing has been applied in plant breeding for fine-mapping of QTLs and for the introgression of desired QTL alleles from wild donors into elite cultivars
[35-37]. In crop-to-wild gene flow, repeated backcrossing to the wild parent might take place along with selfing as a result of the often much higher frequency of wild individuals compared to crop-wild hybrids. One of the direct consequences of repeated backcrossing to the wild species is the continuing decrease in crop genomic segments, both in size as they become successively shorter and in frequency as each plant has fewer segments. Consequently, each backcrossing event is expected to reduce the detection power of QTL analysis [38]. Consistently with this, we detected more QTLs in the $\mathrm{BC}_{1}$ population than in the $\mathrm{BC}_{2}$ population for each of the considered vigour traits. However, despite the decreasing crop content, new QTLs with an additive effect from the crop allele were detected in the backcross populations, including the $\mathrm{BC}_{2}$, as compared to the $\mathrm{F}_{2}$, which we have studied in earlier work [Uwimana et al. submitted]. In the $\mathrm{F}_{2}$ study [Uwimana et al. submitted], plant height QTLs in the $F_{2}$ population were entirely inherited from the wild parent. In this study, two additional plant height QTLs were mapped for the nutrient deficiency treatment $(L-1-1$ and $L-3-3)$ in the $\mathrm{BC}_{1}$ population with an additive effect from the crop. In the $\mathrm{BC}_{2}$ population we detected two more QTLs for plant height (L-4-4 and $L-8-2)$ with the same allelic effect in all the treatments which was positive for the crop allele, showing that the contribution of the crop to plant vigour could be underestimated depending on the population studied.

\section{Common QTLs in selfing and backcrossing hybrid generations}

We found QTL regions related to vigour under control and three abiotic stress conditions, showing a diverse potential introgression mosaic with contributions of genomic segments from both crop and wild relative parents. Many of these QTLs co-localised, allowing to pinpoint introgression "hotspots". Seven QTLs were common between $\mathrm{F}_{2}, \mathrm{BC}_{1}$ and $\mathrm{BC}_{2}$ populations on LG4, LG7 and LG9, three were common in at least two populations on LG1 and LG5, and one QTL was found in very closely located regions in the backcross populations on LG4 (Table 4). A common finding in plant breeding is that different QTLs are detected in different mapping populations of the same cross. The differences could be attributed to statistical power, especially with a limited number of lines in the population $(<200)$, and to a combination of recessiveness and a skewed linkage map [39]. Differences in detected QTLs between populations has also been associated with changes in genetic variation between populations with further backcrossing associated with decreasing genetic variation and consequently resulting in decreasing QTL detection power [38]. In the present study, the QTLs common to more 
Table 3 Significant QTL $\times$ QTL interactions in the $B C_{1}$ and $B C_{2}$ populations, their explained phenotypic variance and the predicted means per genotype combination

\begin{tabular}{|c|c|c|c|c|c|c|c|}
\hline \multirow[b]{2}{*}{ Population } & \multirow[b]{2}{*}{ Treat. } & \multirow[b]{2}{*}{ Trait } & \multirow[b]{2}{*}{ QTLxQTL } & \multicolumn{4}{|c|}{$\begin{array}{l}\% \text { expl. variance Predicted mean per genotype } \\
\text { combination }^{1}\end{array}$} \\
\hline & & & & $h / h$ & $h / b$ & $\mathrm{~b} / \mathrm{h}$ & $b / b$ \\
\hline \multirow[t]{17}{*}{$\mathrm{BC}_{1}$} & Control-D & Plant height & $L-1-1 \times D W-4-65$ & 30.71 & 30.30 & 30.54 & 31.86 \\
\hline & & Dry weight & $L-1-1 \times R M C-8-44$ & 2.947 & 3.10 & 2.832 & 2.578 \\
\hline & & Relative moisture content & $L-7-1 \times L-5-24$ & 93.98 & 93.74 & 93.84 & 93.98 \\
\hline & & & $L-7-1 \times R M C-5-15$ & 94.09 & 93.62 & 93.96 & 93.89 \\
\hline & & & $L-1-1 \times L-5-24$ & 93.77 & 93.95 & 94.00 & 93.8 \\
\hline & Control-SN & Plant height & $L-9-1 \times R M C-5-14$ & 26.14 & 27.20 & 29.29 & 33.79 \\
\hline & & & $L-3-3 \times R M C-8-45$ & 29.76 & 28.49 & 27.46 & 29.94 \\
\hline & & Relative moisture content & $L-1-1 \times L-5-27$ & 92.18 & 92.40 & 92.30 & 92.11 \\
\hline & Salt & Plant height & $L-5-2 \times R M C-8-44$ & 17.85 & 16.61 & 17.01 & 17.68 \\
\hline & & Fresh weight & $D W-9-6 \times R M C-5-15$ & 11.44 & 10.78 & 10.38 & 11.06 \\
\hline & & Relative moisture content & $L-1-1 \times L-5-27$ & 90.07 & 90.34 & 90.25 & 90.02 \\
\hline & & & $L-3-3 \times D W-8-37$ & 90.05 & 90.39 & 90.17 & 90.05 \\
\hline & & & $L-3-3 \times R M C-8-49$ & 90.09 & 90.41 & 90.20 & 90.04 \\
\hline & Nutrient deficiency & Plant height & $L-3-3 \times R M C-8-44$ & 10.56 & 10.19 & 9.62 & 10.16 \\
\hline & & & $D W-8-4 \times R M C-5-15$ & 9.85 & 10.41 & 9.18 & 10.79 \\
\hline & & Dry weight & $L-9-1 \times D W-8-34$ & 0.67 & 0.59 & 0.58 & 0.58 \\
\hline & & Relative moisture content & $D W-8-3 \times D W-9-65$ & 80.17 & 80.87 & 81.53 & 80.86 \\
\hline \multirow[t]{23}{*}{$\mathrm{BC}_{2}$} & Control-D & Plant height & $L-7-1 \times L-8-25$ & 28.87 & 29.04 & 31.06 & 28.69 \\
\hline & & Fresh weight & $F W-1-2 \times D W-9-65$ & 37.80 & 40.99 & 41.41 & 37.33 \\
\hline & & & $L-3-3 \times R M C-6-38$ & 29.61 & 40.00 & 39.01 & 38.89 \\
\hline & & & $L-7-1 \times L-3-38$ & 33.83 & 39.58 & 41.74 & 38.49 \\
\hline & & Relative moisture content & $L-9-1 \times D W-4-611$ & 93.43 & 92.82 & 92.82 & 92.77 \\
\hline & & & $L-4-4 \times L-8-24$ & 92.77 & 93.04 & 92.85 & 92.78 \\
\hline & Drought & Plant height & $L-7-1 \times L-8-25$ & 14.42 & 14.29 & 15.11 & 14.02 \\
\hline & Control-SN & Plant height & $L-7-1 \times L-8-25$ & 21.20 & 20.69 & 23.71 & 21.16 \\
\hline & & Fresh weight & $L-4-4 \times D W-9-68$ & 19.65 & 17.22 & 16.97 & 17.76 \\
\hline & & & $L-3-3 \times R M C-6-37$ & 14.89 & 18.04 & 17.94 & 17.70 \\
\hline & & Dry weight & $L-4-4 \times D W-9-68$ & 1.46 & 1.26 & 1.28 & 1.32 \\
\hline & & & $L-3-3 \times R M C-6-33$ & 1.12 & 1.33 & 1.34 & 1.31 \\
\hline & & Relative moisture content & $L-9-1 \times D W-4-67$ & 93.09 & 92.56 & 92.64 & 92.54 \\
\hline & Salt & Plant height & $L-9-1 \times R M C-5-35$ & 16.91 & 16.04 & 16.11 & 16.98 \\
\hline & & Fresh weight & $D W-4-6 \times L-5-24$ & 11.50 & 10.34 & 9.88 & 10.44 \\
\hline & & Dry weight & $L-8-2 \times F W-1-25$ & 0.93 & 0.95 & 0.98 & 0.87 \\
\hline & Nutrient deficiency & Plant height & $L-7-1 \times F W-1-26$ & 10.95 & 11.37 & 11.68 & 11.26 \\
\hline & & Fresh weight & $L-7-1 \times F W-1-26$ & 5.42 & 5.70 & 5.47 & 5.06 \\
\hline & & & $R M C-1-3 \times R M C-5-35$ & 5.73 & 5.20 & 5.19 & 5.41 \\
\hline & & Relative moisture content & $L-9-1 \times D W-4-66$ & 87.87 & 86.45 & 86.84 & 86.56 \\
\hline & & & $D W-4-6 \times R M C-1-36$ & 86.01 & 87.65 & 86.24 & 86.63 \\
\hline & & & $L-7-1 \times R M C-1-36$ & 85.54 & 86.78 & 86.79 & 86.97 \\
\hline & & & $F W-1-2 \times D W-9-68$ & 86.76 & 86.53 & 86.13 & 86.92 \\
\hline
\end{tabular}

$1 \mathrm{~h}$ : heterozygous genotype, b: homozygous for the wild allele 
Table 4 Recapitulation on common QTLs for vigour in the three hybrid populations $\mathrm{F}_{2}, \mathrm{BC}_{1}$ and $\mathrm{BC}_{2}$ under non-stress (C), drought (D), salt (S) and nutrient deficiency (N) conditions

\begin{tabular}{|c|c|c|c|c|c|c|c|c|c|c|c|c|c|c|}
\hline & & & $F_{2}$ & & & & $\mathrm{BC}_{1}$ & & & & $\mathrm{BC}$ & & & \\
\hline Trait & QTL & LG & $C$ & D & $\mathrm{N}$ & $S$ & $\mathrm{C}$ & D & $\mathrm{N}$ & $\mathrm{S}$ & $C$ & D & $\mathrm{N}$ & $\mathrm{s}$ \\
\hline \multirow[t]{2}{*}{ Plant height } & $L-7-1$ & 7 & - & & - & - & - & & + & & - & & & - \\
\hline & $L-9-1$ & 9 & - & & - & - & - & & - & - & & & & - \\
\hline \multirow[t]{4}{*}{ Fresh weight } & $F W-7-2$ & 7 & & + & + & + & + & + & + & + & + & + & + & + \\
\hline & $F W-8-1$ & 8 & + & & - & + & & & & + & & + & + & + \\
\hline & $F W-9-2$ & 9 & & & & + & + & & + & + & & & & \\
\hline & FW-1-2 & 1 & & & & & + & & + & + & + & & & + \\
\hline \multirow[t]{2}{*}{ Dry weight } & $D W-7-3$ & 7 & - & + & & & + & + & + & + & + & + & + & + \\
\hline & $D W-4-6$ & 4 & & & & & - & & - & & - & - & & \\
\hline \multirow[t]{3}{*}{ Relative moisture content } & $R M C-4-3$ & 4 & + & + & + & & + & + & + & + & & + & + & + \\
\hline & RMC-5-1 & 5 & + & + & & & + & & & & & & & \\
\hline & $R M C-7-4$ & 7 & + & & - & + & - & - & - & & + & & - & \\
\hline
\end{tabular}

The positive sign shows a positive effect for the crop allele and the negative sign shown a positive effect for the wild allele

than one hybrid generation were those with the greatest effects in terms of explained phenotypic variance per treatment and per trait, while the QTLs with small effect were mostly mapped in one hybrid generation.

Linkage groups 4, 7 and 9 were the most important in $\mathrm{BC}_{1}$ and $\mathrm{BC}_{2}$ populations as they showed regions that contained many and common QTLs in the two populations. The same regions were important in the $\mathrm{F}_{2}$ population [Uwimana et al. submitted]. Despite the overlapping QTL regions across hybrid populations, some QTLs showed treatment specificity per population. For instance, $L-7-1$ had a positive effect for the wild allele under nutrient deficiency conditions in the $F_{2}$ population, but the same QTL region showed a positive effect for the crop allele under the same treatment in the $\mathrm{BC}_{1}$ population and it was not significant in the $\mathrm{BC}_{2}$ population. Conversely, RMC-4-3 was consistent across populations and treatments with a positive allelic effect from the crop, though it was not significant in the salt treatment of the $F_{2}$ population. Such QTLxE interactions suggest that the regions might contain different treatment-specific genes which contribute to the vigour of the plants. Moreover, QTLs for different vigour traits were mapped in those same regions with opposite allelic effect. Nevertheless, the involvement of the same regions in the vigour of the hybrids in three populations indicates that these regions will be under selection, either positive or negative, depending on the prevailing conditions.

\section{Epistasis}

QTL epistatic effect was significant for several vigour traits in the two backcross populations. Epistasis has been suggested as one of the major allelic interactions affecting fitness in self-pollinating species such as
Arabidopsis thaliana [40] and rice [41]. Epistatic QTL effects are expected to play a major role in selfing populations and to decline with further backcrossing as a result of decreasing genetic variation [38]. Our results show that the vigour traits were affected by the epistatic effect of QTLs under stress and non-stress conditions, and that positive epistatic effects were mostly associated with genotype combinations involving the crop alleles. QTL epistatic effect in $\mathrm{BC}_{1}$ and $\mathrm{BC}_{2}$ populations emphasizes the genetic importance of the crop genomic segments even after two backcrosses to the wild parent. Importantly, the combination of beneficial epistatic and additive allelic effects from two parents at different loci in repulsion phase has been associated with the origin of transgressive segregation that leads to the creation of superior or even ecologically diverging phenotypes $[12,42,43]$. However, the fact that none of the QTL epistatic effects were detected in both populations makes the stability of the epistatic effect over generations questionable; in turn, this will make it difficult to predict the effect in further generations.

\section{Conclusions}

Both in the $\mathrm{BC}_{1}$ and $\mathrm{BC}_{2}$, lines were identified that performed equally or better than both the wild parental genotype and the additional wild genotype included in the experiments, indicating the occurrence of transgressive segregation in our hybrid populations. Epistasis may be an important underlying factor and some positive epistatic effects of QTLs were detected, mostly associated with crop alleles, but these were not universal across $F_{2}$ and $B C$ generations. Knowledge of fitness effects of crop genomic blocks (QTLs) may be put to use to control (trans)gene flow to natural populations, namely by inserting genes that one would prefer to keep 
contained, into genomic regions disadvantageous to the plant's performance in the field. Although fewer QTLs were detected in the $\mathrm{BC}_{2}$ than in the $\mathrm{BC}_{1}$ and there was also some variation in QTLs between the $\mathrm{F}_{2}$ and the $\mathrm{BC}$ generations, many QTLs were found to be in common between hybrid generations. Among these, there were QTLs for which the crop alleles were clearly disadvantageous to the plant's performance and QTLs for which the crop alleles were advantageous. The latter genomic areas would not be advisable for inserting genes to be contained. It was also possible to identify "hotspots" of QTLs, which would also better be avoided as they are clearly important to the plant's performance and mostly show advantageous as well as disadvantageous effects for the respective crop alleles. This study was carried out on plant vigour, based on the previous knowledge that lettuce crop-wild hybrids undergo selection at an early stage of growth [9]. To our knowledge, this is the first study on introgression that combines a QTL analysis approach with different stress treatments to address the process of introgression. Although these experiments were conducted using a limited number of hybrid genotypes (the hybrids were derived from a cross between single crop and wild genotypes) and under greenhouse conditions, the results constitute a first, informative step towards understanding the potential for introgression of cultivated lettuce genomic segments into wild lettuce under abiotic stress conditions. Future experiments should consider the whole life cycle of hybrid plants from seed germination to seed production under field conditions, as to include early and late plant vigour, natural selection and survival, and reproduction as well as a greater range of crop and wild genotypes.

\section{Methods}

\section{Creation of $\mathrm{BC}_{1}$ and $\mathrm{BC}_{2}$ hybrid progenies and genotyping}

The present study concerns two backcross populations, $\mathrm{BC}_{1}$ and $\mathrm{BC}_{2}$, back-crossed to L. serriola to mimic an important pathway for natural introgression from a crop to its wild relative. Flowers from the $F_{1}$ hybrid plant resulting from a cross between L. serriola (collected from Eys, the Netherlands) [44], and L. sativa (cv. Dynamite) were hand-pollinated with pollen from the L. serriola parental line to generate $\mathrm{BC}_{1}$ plants according to the lettuce pollination protocols by Nagata [45] and Ryder [46]. By the same method, $\mathrm{BC}_{2}$ plants were created using the same $L$. serriola parental line.

The Compositae Genome Project has developed 1083 Single Nucleotide Polymorphism (SNP) markers in lettuce from disease resistance and developmental genes http://compgenomics.ucdavis.edu/compositae_SNP.php. From the 1083 SNPs, a customised Illumina GoldenGate array of 384 SNPs was developed specifically for the markers showing polymorphism between the parents used in our crop-wild cross and with approximately even genetic distribution [Uwimana et al. submitted]. A set of $192 \mathrm{BC}_{1}$ individuals were genotyped using the 384 SNP custom array. Based on their genotypes, $100 \mathrm{BC}_{1}$ individuals were selected that optimized the genetic diversity of the population using the program "Genetic Distance Optimization program" (GDOpt), [47]; and these were used in greenhouse experiments. Forty-five of the $100 \mathrm{BC}_{1}$ plants were backcrossed to L. serriola to generate $\mathrm{BC}_{2}$ lines. At the same time, the $\mathrm{BC}_{1}$ lines were left to self-pollinate to $\mathrm{BC}_{1} \mathrm{~S}_{1}$ seeds (Additional file 1: Figure S1). Six hundred $\mathrm{BC}_{2}$ individuals $\left(12 \mathrm{BC}_{2}\right.$ plants for each of the 45 back-crossed $\mathrm{BC}_{1}$ individuals) were selfed to produce $\mathrm{BC}_{2} \mathrm{~S}_{1}$ seeds. Four hundred fiftyeight $\mathrm{BC}_{2}$ individuals were randomly selected and genotyped with the customized 384 SNP array. Based on their genotypes, a selection of $100 \mathrm{BC}_{2}$ individuals was also made using the program GDOpt and their $\mathrm{BC}_{2} \mathrm{~S}_{1}$ progenies were used in greenhouse experiments.

\section{Greenhouse experiments}

The $\mathrm{BC}_{1} \mathrm{~S}_{1}$ and $\mathrm{BC}_{2} \mathrm{~S}_{1}$ seeds of the selected $100 \mathrm{BC}_{1}$ and $100 \mathrm{BC}_{2}$ individuals were used in greenhouse experiments together with their parents (L. serriola/Eys and $L$. sativa cv. Dynamite). We also included two lines, $L$. serriola acc. UC96US23 and L. sativa cv. Salinas (parents of the reference RIL population used in various experiments $[48,49])$, which, together with the parents of our population, were used to estimate the environmental error. Our parents and the two additional lines were replicated 12 times per treatment and each $\mathrm{BC}_{1}$ and $\mathrm{BC}_{2}$ individual was represented by $12 \mathrm{BC}_{1} \mathrm{~S}_{1}$ and $\mathrm{BC}_{2} \mathrm{~S}_{1}$ seedlings, respectively, per treatment.

Experiments were conducted separately for the $\mathrm{BC}_{1}$ and $\mathrm{BC}_{2}$ populations, using the same set as in the $\mathrm{F}_{2}$ experiments [Uwimana et al. submitted]. For each population, two experiments were carried out, one comprising salt and nutrient treatments together with a control treatment and another experiment comprising a drought treatment together with a control treatment. The drought experiment for the $\mathrm{BC}_{1}$ population was carried out in the period of February-March 2009, the salt and nutrient experiment for the $\mathrm{BC}_{1}$ population was carried out in April-May 2009, the drought experiment for the $\mathrm{BC}_{2}$ population was carried out in November 2009-January 2010 and the salt and nutrient experiment of the same population was carried out in January-March 2010. After transplanting, the plants were watered twice a week with 1.3 EC nutrient solution for two weeks, after which the stress treatments were applied. For the drought treatment, the plants were not given water for three weeks; for salt treatment, irrigation nutrient solution was supplemented with $100 \mathrm{mM} \mathrm{NaCl}$, and for 
nutrient deficiency treatment, plants were irrigated with water without nutrients for three weeks. At the end of the fifth week after transplanting (at the rosette stage) we measured plant vigour for individual plants as shoot height, shoot fresh weight and shoot dry weight (after drying at $80^{\circ} \mathrm{C}$ for 3 days). We calculated shoot relative moisture content as the ratio of the amount of water in the shoot to the total shoot weight [(fresh weight-dry weight)*100/fresh weight].

\section{Construction of the linkage maps}

Out of 384 SNP markers, 347 were successfully scored in the $100 \mathrm{BC}_{1}$ individuals and 348 in the $458 \mathrm{BC}_{2}$ individuals. Genetic linkage maps of the two populations were built separately using JoinMap ${ }^{\mathbb{B}} 4$ [50]. The marker grouping into linkage groups in the $\mathrm{BC}_{2}$ population was kept the same as in the $\mathrm{BC}_{1}$ and $\mathrm{F}_{2}$ populations, and the order of the markers and their genetic distances were calculated based on recombination among the $\mathrm{BC}_{2}$ individuals. The linkage maps were displayed using MapChart 2.2 [51].

\section{Analysis of phenotypic data}

Statistical analysis was performed using GenStat 14th Edition [52]. The drought and the salt-nutrient experiments were analysed separately for each of the $\mathrm{BC}_{1}$ and $\mathrm{BC}_{2}$ populations. The significance of the different terms was determined by the analysis of variance, fitting the model Response $=$ general mean + block + genotype + treatment + genotype.treatment + error; with the term genotype representing the hybrid families (100 $\times 12 \mathrm{BC}_{1} \mathrm{~S}_{1}$ or $100 \times 12 \mathrm{BC}_{2} \mathrm{~S}_{1}$ ). For the QTL analysis, broad sense heritability of family means of the traits in each of the experimental populations was estimated for each treatment as the proportion of the total variance accounted for by the genetic variance using the formula:

$$
H^{2}=V g /(V g+V e / r) ;
$$

where $V g$ is the genetic variance for the $\mathrm{BC}_{1} \mathrm{~S}_{1}$ or $\mathrm{BC}_{2} \mathrm{~S}_{1}$ families, $V e$ is the environmental variance, and $r$ is the number of replications [53]. $V g$ was estimated based on the restricted maximum likelihood (REML) method from the mixed model:

Response $=$ general mean + block + genotype + error;

with the term genotype taken random. Because $\mathrm{BC}_{1} \mathrm{~S}_{1}$ and $\mathrm{BC}_{2} \mathrm{~S}_{2}$ families were segregating, the term $V e$ was the error variance derived from a one-way analysis of variance of the model:

$$
\text { Response }=\text { general mean }+ \text { block }+ \text { parents }+ \text { error; }
$$

with the term parents representing the two parents ( $L$. serriola/Eys and L. sativa cv. Dynamite) and the two added lines (L. serriola acc. UC96US23 and L. sativa $\mathrm{cv}$. Salinas).

\section{Quantitative Trait Loci analysis}

The genetic linkage map, the genotype scores and the phenotypic means were combined for QTL analysis using the QTL analysis function of GenStat 14th Edition [52]. To adjust for the calculation differences caused by the marker gaps due to the additional recombination event in the $\mathrm{BC}_{2}$ population, the gaps in the $\mathrm{BC}_{2}$ linkage map were filled with virtual markers which were given missing marker scores. Thirty-five virtual markers were added on seven linkage groups (LG1, 2, 3, 4, 5, 8 and 9), keeping a maximum distance of $12 \mathrm{cM}$ between the markers (Figures 1, 2, 3, 4 and 5). This resulted in the best estimate of a QTL region, but the presence of QTLs in the $\mathrm{BC}_{1}$ and $\mathrm{BC} C_{2}$ populations were analyzed separately.

In order to effectively model genotype by environment interaction (GxE, with environments represented by the different treatments) through QTL by environment interaction (QTLxE), each trait was analysed individually using the single trait - multiple environment option of the program. Genome-wide association between markers and traits was decided based on a significance level of 0.05 corrected for multiple tests using the $\mathrm{Li}$ and $\mathrm{Ji}$ method [54]. After the selection of the best variancecovariance model for the treatments [55], the candidate QTLs were determined by initial genome scan. Final QTL positions were determined by composite interval mapping taking into account co-factors. The allelic effect of the detected QTLs in each treatment, the effect of QTLxE and the explained phenotypic variance of each QTL per treatment were determined by running a backward selection on the candidate QTLs in a mixed linear model, taking the QTL effect in each treatment as fixed terms and the interaction between each hybrid family and the treatment as random [56]. In that way, each QTL detected in one treatment was tested for its effect and significance in the other treatments.

To test for QTL epistatic effect (QTL $\times$ QTL), the phenotypic means were regressed against the genotypes of the most significant markers for each QTL in a generalized linear model. One marker was considered for each QTL region, and no QTL interaction was estimated for QTLs on the same LG. For each treatment, every trait was explained by the main effects of all the detected QTLs to which interaction between one pair of QTLs was added at a time. The interaction effects of the QTL regions that were significant in the $\mathrm{BC}_{1}$ population were also included in the QTLxQTL analysis in 
$\mathrm{BC}_{2}$. QTLxQTL interaction was decided significant at a level of 0.05 corrected for the number of the traits using the Bonferroni method [57].

\section{Additional material}

Additional file 1: Below is the link to the electronic supplementary material. Figure S1. Crossing and experimental scheme of the study on introgression process from cultivated to wild lettuce. The backcrossing pathway ( $B C_{1}$ and $B C_{2}$ populations) is the subject of this study. Figure $S 2$. Allelic composition of the selected $\mathrm{BC}_{1}(\mathrm{~A})$ and $\mathrm{BC}_{2}(\mathrm{~B})$ genotypes. Blue: homozygous for the wild allele; yellow: hetereozygous; black: missing genotype scores. Backcrossing to the wild parent reduces the crop genome content in amount and in segment size. Figure S3. Boxplots representing the phenotypic variation among $B C_{1} S_{1}$ relative to $L$. serriola acc. UC96US23 (P1), L. sativa cv. Salinas (P2), L. serriola/Eys (P3) and L. sativa $\mathrm{CV}$. Dynamite (P4) for vigour traits dry weight (A), fresh weight (B), plant height (C) and relative moisture content (D) under the five treatments. Figure S4. Boxplots representing the phenotypic variation among $\mathrm{BC}_{2} \mathrm{~S}_{1}$ plants relative to $L$. serriola acc. UC96US23 (P1), L. sativa CV. Salinas (P2), L. serriola/Eys (P3) and L. sativa Cv. Dynamite (P4) for vigour traits dry weight (A), fresh weight (B), plant height (C) and relative moisture content $(D)$ under the five treatments.

\section{Acknowledgements}

This study was financially supported by the Netherlands Organization for Scientific Research (NWO) through their research programme "Ecology Regarding Genetically modified Organisms" (ERGO). The contributions of Leah K. McHale and Richard W. Michelmore were supported by the National Science Foundation Plant Genome Program Grant \#: DBI0421630.

\section{Author details}

'Wageningen UR Plant Breeding, Postbus 386, 6700AJ Wageningen, the Netherlands. 'Wageningen UR Plant Breeding, Postbus 16, 6700AA Wageningen, the Netherlands. ${ }^{3}$ Centre for Ecology \& Hydrology, Maclean Building, Benson Lane, Crowmarsh Gifford, Wallingford, Oxfordshire, OX10 8BB, UK. ${ }^{4}$ Institute for Biodiversity and Ecosystem Dynamics, University of Amsterdam, Postbus 94248, 1090 GE Amsterdam, the Netherlands. ${ }^{5}$ Wageningen UR Plant Biometris, Postbus 100, 6700AC Wageningen, the Netherlands. ${ }^{6}$ Department of Horticulture and Crop Science, The Ohio State University, Columbus, OH 43210, USA. ${ }^{7}$ Genome Center and Department of Plant Sciences, University of California Davis, Davis, CA 95616-8816, USA.

\section{Authors' contributions}

$\mathrm{BU}$ conducted this work as part of her PhD thesis. She contributed to the creation of the hybrids and the design of the study. She carried out the experiments, collected the data, performed statistical analysis, linkage mapping and QTL analyses and drafted the manuscript. MJMS, CCMvdW, PHVT and RGFV conceived and designed the study and supervised the work. DAPH conceived and designed the study and generated the hybrids. YH generated the hybrids and participated in the design of the experiments. JJ contributed to statistical and QTL analysis. LKMcH and RWM developed the SNP markers and were involved in genotyping the samples. All authors critically reviewed the manuscript. All authors read and approved the final manuscript.

Received: 18 December 2011 Accepted: 26 March 2012 Published: 26 March 2012

\section{References}

1. Van de Wiel C, Groot M, Den Nijs H: Gene flow from crops to wild plants and its population-ecological consequences in the context of GM-crop biosafety, including some recent experiences from lettuce. In In Environmental Costs and Benefits of Transgenic Crops. Wageningen UR Frontis Series Volume 7. Edited by: Wesseler J. Dordrecht: Springer; 2005:97-110.
2. Pilson D, Prendeville HR: Ecological effects of transgenic crops and the escape of transgenes into wild populations. Annu Rev Ecol Evol Syst 2004, 35:149-174.

3. Snow AA, Andow DA, Gepts P, Hallerman EM, Power A, Tiedje JM, Wolfenbarger LL: Genetically engineered organisms and the environment: current status and recommendations. Ecol Appl 2005, 15:377-404.

4. Tiedje JM, Colwell RK, Grossman YL, Hodson RW, Lenski RE, Mack RN, Regal PJ: The planned introduction of genetically engineered organisms: ecological considerations and recommendations. Ecology 1989, 70:298-315

5. Ellstrand NC: Current knowledge of gene flow in plants: implications for transgene flow. Philos Trans R Soc Lond B 2003, 358:1163-1170.

6. Ellstrand NC, Prentice HC, Hancock JF: Gene flow and Introgression from domesticated plants into their wild relatives. Annu Rev Ecol Syst 1999, 30:539-563.

7. Baack EJ, Sapir Y, Chapman MA, Burke JM, Rieseberg LH: Selection on domestication traits and quantitative trait loci in crop-wild sunflower hybrids. Mol Ecol 2008, 17:666-677.

8. Dechaine JM, Burger JC, Chapman MA, Seiler GJ, Brunick R, Knapp SJ, Burke JM: Fitness effects and genetic architecture of plant-herbivore interactions in sunflower crop-wild hybrids. New Phytol 2009, 184:828-841.

9. Hooftman DAP, Hartman Y, Oostermeijer JGB, Den Nijs HCM: Existence of vigorous lineages of crop-wild hybrids in Lettuce under field conditions. Environ Biosafety Res 2009, 4:203-217.

10. Snow AA, Pilson D, Rieseberg LH, Paulsen MJ, Pleskac N, Reagon MR, Wolf DE, Selbo SM: A Bt transgene reduces herbivory and enhances fecundity in wild sunflower. Ecol Appl 2003, 13:279-286.

11. Burke JM, Arnold ML: Genetics and the fitness of hybrids. Annu Rev Genet 2001, 35:31-52

12. Lexer $C$, Welch ME, Raymond O, Rieseberg LH: The origin of ecological divergence in Helianthus paradoxus (Asteraceae): selection on transgressive characters in a novel hybrid habitat. Evolution 2003, 57:1989-2000.

13. Rieseberg $L H$, Archer MA, Wayne RK: Transgressive segregation, adaptation and speciation. Heredity 1999, 83:363-372.

14. Hooftman DAP, Flavell AJ, Jansen H, Den Nijs HCM, Syed NH, Sørensen AP, Orozcoter Wengel P, Van de Wiel CCM: Locus-dependent selection in crop-wild hybrids of lettuce under field conditions and its implication for GM crop development. Evol Appl 2011, 4:648-659.

15. Koopman WJM, Li Y, Coart E, van de Weg WE, Vosman B, Roldán-Ruiz I, Smulders MJM: Linked versus unlinked markers: multilocus microsatellite haplotype sharing as a tool to estimate gene flow and introgression. Mol Ecol 2007, 16:243-256.

16. Barton NH: Genetic hitchhiking. Philos Trans Roy Soc Lond B 2000, 355:1553-1562.

17. Kwit C, Moon HS, Warwick SI, Stewart CN Jr: Transgene introgression in crop relatives: molecular evidence and mitigation strategies. Trends Biotechnol 2011, 29:284-293.

18. Stewart CN Jr, Halffill MD, Warwick Sl: Transgene introgression from genetically modified crops to their wild relatives. Nature Rev Genet 2003, 4:806-817.

19. Chapman MA, Burke JM: Letting the gene out of the bottle: the population genetics of genetically modified crops. New Phytol 2006, 170:429-443.

20. De Vries IM: Crossing experiments of lettuce cultivars and species (Lactuca sect. Lactuca, Compositae). Plant Syst Evol 1990, 171:233-248.

21. D'Andrea L, Felber F, Guadagnuolo R: Hybridization rates between lettuce (Lactuca sativa) and its wild relative (L. serriola) under field conditions. Environ Biosafety Res 2008, 7:61-71.

22. Thompson RC, Whitaker TW, Bohn GW, Van Horn CW: Natural crosspollination in lettuce. Am Soc Hort Sci 1958, 72:403-409.

23. Uwimana B, D'Andrea L, Felber F, Hooftman DAP, den Nijs HCM, Smulders MJM, Visser RGF, van de Wiel CCM: A Bayesian analysis of gene flow from crops to their wild relatives: cultivated (Lactuca sativa L.) and prickly lettuce ( $L$. serriola $L$.) and the recent expansion of $L$. serriola in Europe. Mol Ecol, doi: 10.1111/j.1365-294X.2012.05489.x.

24. Warner RM, Walworth AE: Quantitative inheritance of crop timing traits in interspecific hybrid petunia populations and interactions with crop quality parameters. J Heredity 2010, 101:308-316. 
25. Dechaine JM, Burger JC, Burke JM: Ecological patterns and genetic analysis of post-dispersal seed predation in sunflower (Helianthus annuus) crop-wild hybrids. Mol Ecol 2010, 19:3477-3488.

26. Song $X$, Wang Z, Zuo J, Huangfu C, Qiang S: Potential gene flow of two herbicide-tolerant transgenes from oilseed rape to wild $B$. juncea var. gracilis. Theor Appl Genet 2010, 120:1501-1510.

27. Boyer JS: Plant productivity and environment. Science 1982, 218:443-448.

28. Munns R, James RA: Screening methods for salinity tolerance: a case study with tetraploid wheat. Plant Soil 2003, 253:201-218.

29. White PJ, Brown PH: Plant nutrition for sustainable development and global health. Ann Bot 2010, 105:1073-1080.

30. Witcombe JR, Hollington PA, Howarth CJ, Reader S, Steele KA: Breeding for abiotic stresses for sustainable agriculture. Philos Trans Roy Soc B 2008, 363:703-716.

31. Tester $M$, Langridge $P$ : Breeding technologies to increase crop production in a changing world. Science 2010, 327:818-822.

32. Truco MJ, Antonise R, Lavelle D, Ochoa O, Kozik A, Witsenboer H, Fort SB, Jeuken MJM, Kesseli RV, Lindhout P, Michelmore RW, Peleman J: A highdensity, integrated genetic linkage map of lettuce (Lactuca spp.). Theor Appl Genet 2007, 115:735-746.

33. Hauser TP, Jørgensen RB, Østergård H: Fitness of backcross and F2 hybrids between weedy Brassica rapa and oilseed rape (B. napus). Heredity 1998 , 81:436-443.

34. Mercer KL, Andow DA, Wyse DL, Shaw RG: Stress and domestication traits increase the relative fitness of crop-wild hybrids in sunflower. Ecol Lett 2007, 10:383-393.

35. Fulton TM, Grandillo S, Beck-Bunn T, Fridman E, Frampton A, Lopez J, Petiard V, Uhlig J, Zamir D, Tanksley SD: Advanced backcross QTL analysis of a Lycopersicon esculentum $\times$ Lycopersicon parviflorum cross. Theor Appl Genet 2000, 100:1025-1042.

36. Ho JC, MCCouch SR, Smith SE: Improvement of hybrid yield by advanced backcross QTL analysis in elite maize. Theor App/ Genet 2002, 105:440-448.

37. Robert VJM, West MAL, Inai S, Caines A, Arntzen JK, Smith JK, StClair DA: Marker-assisted introgression of blackmold resistance QTL alleles from wild Lycopersicon cheesmanii to cultivated tomato L. esculentum) and evaluation of QTL phenotypic effects. Mol Breeding 2001, 8:217-233.

38. Tanksley SD, Nelson JC: Advanced backcross QTL analysis: a method for the simultaneous discovery and transfer of valuable QTLs from unadapted germplasm into elite breeding lines. Theor App/ Genet 1996, 92:191-203.

39. Jeuken MJW, Pelgrom K, Stam P, Lindhout P: Efficient QTL detection for nonhost resistance in wild lettuce: backcross inbred lines versus $F_{2}$ population. Theor App/ Genet 2008, 116:845-857.

40. Malmberg RL, Held S, Waits A, Mauricio R: Epistasis for fitness-related quantitative traits in Arabidopsis thaliana grown in the field and in the greenhouse. Genetics 2005, 171:2013-2027.

41. Mei HW, Luo LJ, Ying CS, Wang YP, Yu XQ, Guo LB, Paterson AH, Li ZK: Gene actions of QTLs affecting several agronomic traits resolved in a recombinant inbred rice population and two testcross populations. Theor App/ Genet 2003, 107:89-101.

42. Latta RG, Gardner KM, Johansen-Morris AD: Hybridization, recombination, and the genetic basis of fitness variation across environments in Avena barbata. Genetica 2007, 129:167-177.

43. Lexer C, Welch ME, Durphy JL, Rieseberg LH: Natural selection for salt tolerance quantitative trait loci (QTLs) in wild sunflower hybrids: implications for the origin of Helianthus paradoxus, a diploid hybrid species. Mol Ecol 2003, 12:1225-1235.

44. Hooftman DAP, Oostermeijer JGB, Jacobs MMJ, Den Nijs HCM: Demographic vital rates determine the performance advantage of cropwild hybrids in lettuce. J Appl Ecol 2005, 42:1086-1095

45. Nagata RT: Clip-and-wash method of emasculation for lettuce. HortSci 1992, 27:907-908.

46. Ryder EJ: Lettuce, Endive and Chicory Wallingford: CAB International; 1999.

47. Odong TL, van Heerwaarden J, Jansen J, van Hintum TJL, van Eeuwijk FA: Statistical techniques for constructing reference sets of accessions and microsatellite markers. Crop Sci 2011, 51:2401-2411.

48. Argyris J, Truco MJ, Ochoa O, Knapp SJ, Still DW, Lenssen GM, Schut JW Michelmore RW, Bradford KJ: Quantitative trait loci associated with seed and seedling traits in Lactuca. Theor Appl Genet 2005, 111:1365-1376.

49. Zhang FZ, Wagstaff C, Rae AM, Sihota AK, Keevil CW, Rothwell SD, Clarkson GJJ, Michelmore RW, Truco MJ, Dixon MS, Taylor G: QTLs for shelf life in lettuce co-locate with those for leaf biophysical properties but not with those for leaf developmental traits. J Exp Bot 2007, 58:1433-1449.

50. Van Ooijen JW: In JoinMap ${ }^{\circledR}$ 4, Software for the calculation of genetic linkage maps in experimental populations. Edited by: Kyazma BV. Wageningen; 2006:

51. Voorrips RE: MapChart: Software for the graphical presentation of linkage maps and QTLs. J Hered 2002, 93:77-78.

52. Payne RW, Murray DA, Harding SA, Baird DB, Soutar DM: An introduction to GenStat for Windows (14th Edition) Hemel Hempstead: VSN International; 2011.

53. Chahal GS, Gosal SS: Principles and procedures of plant breeding: Biotechnological and conventional approaches Harrow: Alpha Science International Ltd.; 2002.

54. Li J, Ji L: Adjusting multiple testing in multilocus analyses using the eigenvalues of a correlation matrix. Heredity 2005, 95:221-227.

55. Malosetti M, Voltas J, Romagosa I, Ullrich SE, van Eeuwijk FA: Mixed models including environmental covariables for studying QTL by environment interaction. Euphytica 2004, 137:139-145.

56. Mathews KL, Malosetti M, Chapman S, Mclntyre L, Reynolds M, Shorter R, van Eeuwijk F: Multi-environment QTL mixed models for drought stress adaptation in wheat. Theor App/ Genet 2008, 117:1077-1091.

57. Bland JM, Altman DG: Multiple significance tests: the Bonferroni method. Brit Med J 1995, 310:170.

doi:10.1186/1471-2229-12-43

Cite this article as: Uwimana et al:: Crop to wild introgression in lettuce: following the fate of crop genome segments in backcross populations. BMC Plant Biology 2012 12:43.

\section{Submit your next manuscript to BioMed Central and take full advantage of:}

- Convenient online submission

- Thorough peer review

- No space constraints or color figure charges

- Immediate publication on acceptance

- Inclusion in PubMed, CAS, Scopus and Google Scholar

- Research which is freely available for redistribution

Submit your manuscript at www.biomedcentral.com/submit
C Biomed Central 